\title{
Letter to the editor: Study Summary - Randomized Control Trial of Omega-3 Fatty Acid Supplementation for the Treatment of COVID-19 Related Olfactory Dysfunction
}

David Lerner $^{*}$ (1), Katherine Garvey, Annie Arrighi-Allisan, Andrey Filimonov, Peter Filip, Katherine Liu, Sen Ninan, Madeleine Schaberg, Patrick Colley, Anthony Del Signore, Satish Govindaraj and Alfred Marc Iloreta

\begin{abstract}
Objectives: To evaluate a therapeutic role for omega-3 fatty acid supplementation in the treatment of olfactory dysfunction associated with COVID-19 infection

Trial design: Randomized, double-blinded, placebo-controlled trial

Participants: Eligible patients are adults with self-reported new-onset olfactory dysfunction of any duration associated with laboratory-confirmed or clinically suspected COVID-19 patients. Exclusion criteria include patients with pre-existing olfactory dysfunction, history of chronic rhinosinusitis or history of sinus surgery, current use of nasal steroid sprays or omega-3 supplementation, fish allergy, or inability to provide informed consent for any reason. The trial is conducted at Mount Sinai Hospital
\end{abstract}

Intervention and comparator: The intervention group will receive $2000 \mathrm{mg}$ daily of omega-3 supplementation in the form of two "Fish Oil, Ultra Omega-3" capsules (product of Pharmavite ${ }^{\circledast}$ ) daily. The comparator group will take 2 placebo capsules of identical size, shape, and odor daily for 6 weeks.

Main outcomes: Each subject will take a Brief Smell Identification Test at study enrolment and completion after 6 weeks. The primary outcome will be change in Brief Smell Identification Test over the 6-week period.

Randomisation: Patients will be randomized by the Investigational Drug Pharmacy at the Icahn School of Medicine at Sinai via a computer-generated sequence in a 1:1 allocation to treatment or control arms.

Blinding (masking): Both participants and researchers will be blinded.

Numbers to be randomised (sample size): There will be 88 participants randomized to each group. A total of 176 participants will be randomized.

Trial Status: Protocol Version 1, 8/3/2020

Recruitment is ongoing, started 8/5/2020 with estimated completion 11/30/2020.

(Continued on next page)

* Correspondence: david.k.lerner.14@gmail.com

Department of Otolaryngology, Icahn School of Medicine at Mount Sinai,

New York, NY, USA

(c) The Author(s). 2020 Open Access This article is licensed under a Creative Commons Attribution 4.0 International License, which permits use, sharing, adaptation, distribution and reproduction in any medium or format, as long as you give appropriate credit to the original author(s) and the source, provide a link to the Creative Commons licence, and indicate if changes were made. The images or other third party material in this article are included in the article's Creative Commons licence, unless indicated otherwise in a credit line to the material. If material is not included in the article's Creative Commons licence and your intended use is not permitted by statutory regulation or exceeds the permitted use, you will need to obtain permission directly from the copyright holder. To view a copy of this licence, visit http://creativecommons.org/licenses/by/4.0/. The Creative Commons Public Domain Dedication waiver (http://creativecommons.org/publicdomain/zero/1.0/) applies to the data made available in this article, unless otherwise stated in a credit line to the data. 
(Continued from previous page)

Trial registration: The trial is registered on ClinicalTrials.gov with Protocol Identifier: NCT04495816.

Trial registration: ClinicalTrials.gov, NCT04495816. Registered 3 August 2020

Full protocol: The full protocol is attached as an additional file, accessible from the Trials website (Additional file 1).

Keywords: COVID-19, Randomised controlled trial, protocol, olfactory dysfunction, omega-3 fatty acid, smell loss

\section{Supplementary Information}

The online version contains supplementary material available at https://doi. org/10.1186/s13063-020-04905-y.

Additional file 1. Full Study Protocol.

\section{Acknowledgements}

Not applicable.

\section{Authors' contributions}

$D L, A F, P F$ - study design, subject recruitment. KG, AA, KL, SN - subject recruitment, literature review. MS, PC, AS, SG - study design, subject recruitment. Al - study design, study oversight. The author(s) read and approved the final manuscript.

\section{Funding}

No funding was received for this study. Study drug and capsules were provided by Pharmavite ${ }^{\circledast}$. Pharmavite ${ }^{\circledast}$ had no role in the design of the study and collection, analysis and interpretation of data and in the writing of the manuscript.

\section{Availability of data and materials}

The final trial dataset will be accessible from the author on reasonable request. Contact David Lerner (e-mail david.lerner2@mountsinai.org).

\section{Ethics approval and consent to participate}

This study protocol was approved by the Institutional Review Board at the Icahn School of Medicine at Mount Sinai on 7/10/2020 (HS\#:20-00511, GCO\#20-1132 ISMMS)

Informed consent will be obtained from all participants. Only adults are included in the study.

\section{Consent for publication}

Not applicable.

\section{Competing interests}

The authors declare that they have no competing interests.

Received: 12 November 2020 Accepted: 15 November 2020 Published online: 23 November 2020

\section{Publisher's Note}

Springer Nature remains neutral with regard to jurisdictional claims in published maps and institutional affiliations. 